\title{
Operating Point Selected Flux-Weakening Control of Induction Motor for Torque-Improved High-Speed Operation under Multiple Working Conditions
} Dol:

10.1109/TPEL.2019.2905536

\section{Document Version}

Accepted author manuscript

Link to publication record in Manchester Research Explorer

Citation for published version (APA):

Dong, Z., Wang, B., Yu, Y., Zhang, X., Zhang, J., Xu, D. G., \& Ding, Z. (2019). Operating Point Selected FluxWeakening Control of Induction Motor for Torque-Improved High-Speed Operation under Multiple Working Conditions. IEEE Transactions on Power Electronics, 1-1. https://doi.org/10.1109/TPEL.2019.2905536

\section{Published in:}

IEEE Transactions on Power Electronics

\section{Citing this paper}

Please note that where the full-text provided on Manchester Research Explorer is the Author Accepted Manuscript or Proof version this may differ from the final Published version. If citing, it is advised that you check and use the publisher's definitive version.

\section{General rights}

Copyright and moral rights for the publications made accessible in the Research Explorer are retained by the authors and/or other copyright owners and it is a condition of accessing publications that users recognise and abide by the legal requirements associated with these rights.

\section{Takedown policy}

If you believe that this document breaches copyright please refer to the University of Manchester's Takedown Procedures [http://man.ac.uk/04Y6Bo] or contact uml.scholarlycommunications@manchester.ac.uk providing relevant details, so we can investigate your claim.

\section{OPEN ACCESS}




\title{
Operating Point Selected Flux-Weakening Control of Induction Motor for Torque-Improved High-Speed Operation under Multiple Working Conditions
}

\author{
Zhen Dong, Student Member, IEEE, Bo Wang, Member, IEEE, Yong Yu, Xu Zhang, Jing Zhang, \\ Dianguo Xu, Fellow, IEEE and Zhengtao Ding, Senior Member, IEEE
}

\begin{abstract}
Due to the requirements of multiple working conditions for induction motor in high-speed flux-weakening operation, conventional "maximum torque oriented" fluxweakening controller reveals its own limitations. This paper focuses on holistic torque performance optimization for multicondition operation. Torque ripple and dynamic response under two kinds of specific working conditions (high-speed braking and load step change) are explicitly analyzed. The theoretically precise maximum torque point is derived to extract the possible output torque for deep flux-weakening operation. Further, an operating point selected flux-weakening controller (OPS-FC) is proposed. It retains the maximum output torque capability for step acceleration and full-load conditions, as well as holding other novel features for the changing working conditions. 1) The selected operating point is automatically manipulated for torque ripple alleviation under non-maximum torque condition. 2) Since the voltage reference in proposed OPS-FC is directly constructed, the system robustness is enhanced. 3) Speed range is extended to the deep flux-weakening operation, and the complex vector decoupling part of $d$-axis current regulator is first applied and shared as a flux-weakening path for closed-loop control. Hence, the complicated PI regulator tuning is averted. The proposed scheme is experimentally verified on a $3.7 \mathrm{~kW}$ commercial platform.
\end{abstract}

Index Terms-Induction motor, flux-weakening control, torque performance improvement, high-speed operation. ${ }^{1}$

\section{NOMENCLATURE}

$\begin{array}{ll}R_{s}, R_{r} & \text { Stator and rotor resistances. } \\ L_{s}, L_{r}, L_{m} & \text { Stator and rotor self-inductances, mutual } \\ & \text { inductance. } \\ \omega_{r}, \omega_{e} & \text { Rotor and excitation angular frequency. }\end{array}$

Manuscript received August 24, 2018; revised January 7, 2019; accepted March 7, 2019. This work was supported in part by National Natural Science Foundation of China (51690182) and (51807038); in prat by grants from the Power Electronics Science and Education Development Program of Delta Group (DREK2017002); in part by China Postdoctoral Science Foundation funded project (2018M630354); and in part by Fundamental Research Funds for the Central Universities (HIT.NSRIF.2019025) Corresponding Author: Bo Wang.

Z. Dong and Z. Ding are with the School of Electrical and Electronic Engineering, The University of Manchester, Manchester, M13 9PL, U.K. (email: zhen.dong-4@ postgrad.manchester.ac.uk; Zhengtao.Ding@manchester. ac.uk).

B. Wang, Y. Yu, X. Zhang, J. Zhang and D. Xu are with the School of Electrical Engineering and Automation, Harbin Institute of Technology, Harbin, China (e-mail: wangbohit@hit.edu.cn; yuyong@hit.edu.cn; zhangxu_hitee@163.com; zhangjing81606@163.com; xudiang@hit.edu.cn).

$\lambda_{r}$
$\sigma=1-L_{m}^{2} /\left(L_{s} L_{r}\right)$
$U_{d c}$
$U_{d c-n o m}$
$n_{p}$
$T_{e}$
$u_{s d}, u_{s q}$
$i_{s d}, i_{s q}$
$i_{s m a x}, u_{s m a x}$
$i_{s d, \text { rated }}$
$i_{s d, \text { weaken }}$
()$_{L P F}$
$k_{e x t}$
$\alpha$
[]$_{r e f}$
[]$^{*}$
[]$_{d},[]_{q}$
[]$_{\alpha},[]_{\beta}$

Rotor flux in synchronous reference. Leakage coefficient. DC-Link voltage.

Nominal value of DC-Link voltage. Number of pole pairs.

Electromagnetic torque.

$d$-axis and $q$-axis stator voltages. $d$-axis and $q$-axis stator currents.

Maximum current and voltage.

Value of $d$-axis current for rated flux Weaken item generated from the fluxweakening controller.

Item processed by a low pass filter. Coefficient of the voltage reference in flux-weakening controller.

Angle between the input voltage vector and the rotor flux vector in $d-q$ frame. Reference quantities.

Command voltage quantities from current regulator.

Quantities on the synchronous rotating $d-q$ reference frame.

Quantities on the stationary $\alpha-\beta$ reference frame.

\section{INTRODUCTION}

High-speed induction motor (IM) drives are extensively adopted in industrial applications such as electrical vehicles (EVs), computational numerical control (CNC) spindle drives, electric locomotives and compressors [1], [2]. Although the IM high-speed control has been developing for more than 20 years, challenge still exists especially when it comes to highrequirement multi-condition applications. High-end $\mathrm{CNC}$ spinning machine is a typical case [3]. In order to achieve the cutting smoothness, the processing efficiency and the cutting precision, multiple working conditions are required in a workpiece process, which include a possibly fast acceleration (deceleration) with high-speed step start (braking), a step load change or an ultimate loading under high-speed operation, extremely wide speed range, etc. Therefore, the entire highspeed control system has to simultaneously possess capabilities like the maximum output torque, the stable wide 


\section{IEEE POWER ELECTRONICS REGULAR PAPER/LETTER/CORRESPONDENCE}

speed range, the high dynamic response as well as the system robustness [4].

Till now, high-speed control schemes can be divided into two categories: direct torque control (DTC) [5] and fieldoriented vector control (FOC) [6], and more information on the classification can be referred in [7]. Considering the intrinsic demerit of hysteresis loops in DTC, [8] and [9] developed deadbeat-direct torque and flux control (DB-DTFC) and finite-settling-steps direct torque and flux control (FSSDTFC), respectively. As potential techniques, DB-DTFC and FSS-DTFC promise the hexagon operation for IM high-speed control. However, the voltage is directly calculated and manipulated based on the motor model. Thus the sensitive to motor parameters requires a combination of advanced current and flux observers and parameter estimation techniques as a reassurance of the control performance [10]. While the DTFCbased high speed control schemes are pending to be further optimized, indirect FOC (IFOC) is widely used and relatively well-developed for IM high-speed applications.

The classical IFOC-based flux-weakening scheme is " $1 / \omega_{r}$ " method which is firstly proposed to extend the speed range to beyond the base speed whilst cannot achieve the maximum torque capability [11]. The voltage closed-loop fluxweakening controller (VCFC) proposed in [12] is an effective method to ensure maximum torque [13]. However, its drawback is that voltage reference in flux-weakening controller is set as an inscribed circle, and thus the utilization of DC-Link voltage is limited. Since higher utilization of DCLink voltage brings in both a larger output torque and a wider speed range, schemes in [14]-[19] contribute to explore the limit capability of inverter. On the other hand, some interests focus on the dynamic response problem in these maximum torque control schemes. [9], [14] point out that the dynamic performance is deteriorated due to the conflict among subcontrol actions in voltage extension region. To address this problem, [19] achieves an optimized coordination control by realizing the boundary consistency of sub-control parts and the torque ripple problem is also highlighted. To strengthen system robustness, [20] employs a low-pass filter in the fluxweakening controller to retard the effect of DC-Link overvoltage, and in [21], the filed harmonics is suppressed to ensure system stability in a wide speed range.

As for the high-speed range, it can be further extended to the deep flux-weakening region if the maximum slip frequency constraint is considered. In that case, the $q$-axis current needs to be reduced. There are three equivalent conditions acting as $q$-axis current limit: (1) current/flux inequality: $i_{s d} \geq \sigma i_{s q}$ or $\lambda_{r} \geq \sigma L_{m} i_{s q}$ [6], [22]; (2) voltage inequality: $\left|u_{s d}\right| \leq u_{s \max } / \sqrt{2} \quad[12] ; \quad$ (3) angle inequality: $\alpha \leq 3 \pi / 4$ [23]. While (1) is an open-loop control, in (2), (3), voltage information is detected for closed-loop control assisted by an additional PI regulator.

Generally, methods mentioned above are still regarded as "maximum-torque-oriented (MTO)" rather than "multicondition-oriented (MCO)", and thus more factors and requirements need to be further considered in the design of flux-weakening control. Moreover, due to the intrinsic characteristics of high-speed system (constraints of maximum current and maximum voltage, and the interactions and limits of subsystems in the control system), the system is actually in a complex and fragile state under the edges of linearity and nonlinearity [24]. Hence, how to make a tradeoff, fit the consistency and realize an overall torque-improved high-speed operation even under multiple working conditions is much important.

This paper aims for the MCO torque optimization and the main contributions are summarized as follows:

1) A theoretical analysis is given on issues for two kinds of important working conditions (i.e., DC-Link overvoltage under high-speed braking, and torque ripple under load change condition). And thus effects on the stability and dynamic performance of the system are illustrated and the guidance for flux-weakening controller design is concluded.

2) An elaborate discussion on the effect of stator resistance on the maximum torque in deep flux-weakening region is presented. Further, the precise $d$-axis voltage for theoretical maximum torque point is derived to ensure a stable operation in an extended speed range.

3) A novel operating point selected flux-weakening controller (OPS-FC) is proposed which can ensure a great performance under multiple working conditions. The controller design takes advantages of the coordination among subsystems and the decoupling path in current regulator is first applied as the flux-weakening feedback path. The proposed OPS-FC retains the maximum torque capability, and furthermore, shows its superiority on less torque ripple, stronger system robustness and more concise tuning process.

The arrangement of this paper is as follows: Section II is a brief review of basic maximum torque control theory and a comparison of VCFS-based methods. Section III contains three aspects: an explicit analysis of relationship among DCLink voltage, maximum torque, and torque ripple; a discussion on operating point selection for torque ripple alleviation; and a theoretical analysis of maximum torque point for deep fluxweakening region. In Section IV, the OPS-FC is proposed and analyzed, and especially, the feasibility for deep fluxweakening operation is illustrated. The experimental results are shown in Section V.

\section{IM MAXIMUM TORQUE CONTROL IN HIGH-SPEED REGION}

\section{A. Ideal Maximum Torque Oriented (MTO) Control for High Speed Operation of IM}

In $d$ - $q$ frame, combining the simplified IFOC-based IM voltage equation (neglecting the stator resistance part and the dynamic part) and torque equation, the limitations of IM highspeed operation can be expressed in voltage form and current form as [6], [12]:

$$
\left\{\begin{array}{l}
u_{s d}^{2}+u_{s q}^{2} \leq u_{s \max }^{2} \\
\left|u_{s d}\right| \leq u_{s \max } / \sqrt{2} \\
\left(u_{s d} / \omega_{e} \sigma L_{s}\right)^{2}+\left(u_{s q} / \omega_{e} L_{s}\right)^{2} \leq i_{s \max }^{2},
\end{array}\right.
$$




\section{IEEE POWER ELECTRONICS REGULAR PAPER/LETTER/CORRESPONDENCE}

and

$$
\left\{\begin{array}{l}
i_{s d}^{2}+i_{s q}^{2} \leq i_{s \max }^{2} \\
i_{s d} \geq \sigma i_{s q} \\
\left(\omega_{e} L_{s} i_{s d}\right)^{2}+\left(\omega_{e} \sigma L_{s} i_{s q}\right)^{2} \leq u_{s \max }^{2} .
\end{array}\right.
$$

Regarding $u_{\text {smax }}$ and $i_{\text {smax }}$ as constant values, the ideal voltage vector trajectory (blue segment O-C-D in left half plane) and current vector trajectory (red segment A-B-O in right half plane) for IM maximum output torque are shown in Fig. 1.

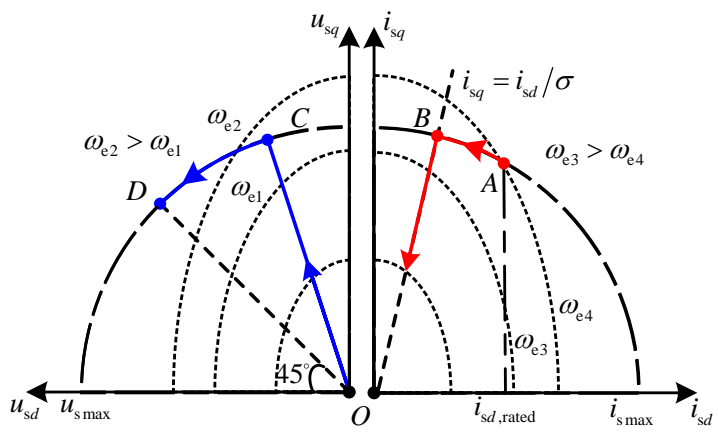

Fig. 1. Ideal voltage (left half plane) and current (right half plane) vector trajectory for IM maximum output torque.

Several MTO methods have been proposed to drive the voltage and current vector to run along the ideal trajectory. They can be divided as 1) model based method [25],2) current error based method [26], 3) look up table method [27], 4) voltage error based method [14], and related classification can be found in [18]. Among these, as one kind of voltage error based methods, the VCFC has been proved its superiority in terms of simple realization and general application [20].

\section{B. Comparison of conventional VCFC-based Methods}

The basic structure of VCFC is shown in Fig. 2(a) and the voltage reference is set to $U_{d c} / \sqrt{3}$ ( the radius of inscribed circle in SVPWM). Once the amplitude of voltage vector exceeds the reference value, a weaken item will be generated through a PI controller with limit and added to the set $d$-axis current reference. Since the VCFC is a closed-loop controller, a proper weakening flux is always obtained as the speed increases. Different from the current limit $i_{\text {smax }}$ that is commonly set under a certain condition, the voltage limit is determined by the inverter output capability with coordination of the PWM modulation strategy. When the voltage trajectory migrates out of the inscribed circle and into the voltage extension region, the instantaneous torque increases as the result of the higher utilization of DC-Link voltage. It is important for flux-weakening control to operate in overmodulation region so as to obtain fast acceleration capability and maximum output torque [17]. Fig. 2(b) Fig. 2(e) depict a series of VCFC-based MTO schemes and more explanation can be found in [19]. The method in Fig. 2(b) extends the voltage reference by adjusting the coefficient $k_{u t}$, and satisfies $k_{u t l} \leq 1$. Methods in Fig.2(c) use the error between switching time and active switching time to build the flux-weakening controller, which guarantees the hexagon operation at high speed. In Fig. 2(d), the reconstructed voltage after overmodulation is employed as the voltage reference. Fig. 2(e) utilizes the adjustable voltage reference by comparing the value of adjusted extended circle and the reconstructed voltage. However, since the improvement of maximum torque meanwhile brings in the negative effects like inevitable torque ripple, to objectively evaluate their control performance, 5 performance indexes are defined considering the requirements of multiple working conditions. They are the utilization of DC-Link voltage (UDLV), the torque ripple under maximum torque condition (TRMT), the torque ripple under nonmaximum torque condition (TRNT), the independence on voltage reconstruction (IVR), and the rejection of DC-Link overvoltage (RDO), respectively. The ranking score 1 indicates regular performance, score 2 indicates adjustable or modified performance and score 3 indicates excellent performance.
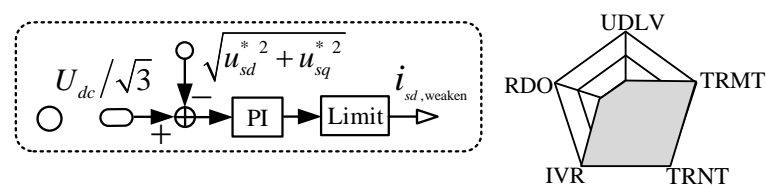

(a) Method in [12]
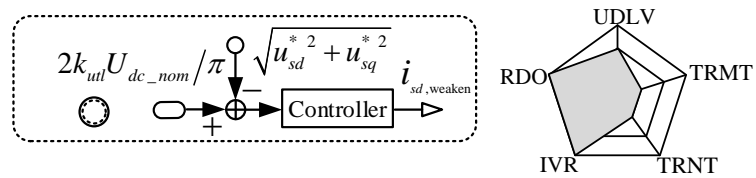

(b) Method in [15]

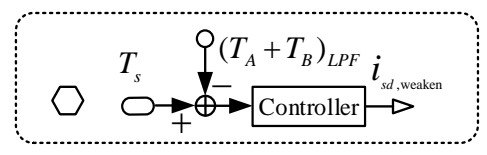

(c) Method in [18], [27]
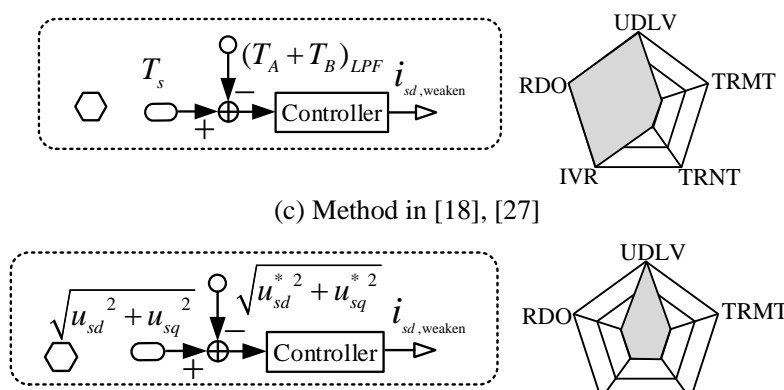

(d) Method in [14], [16]
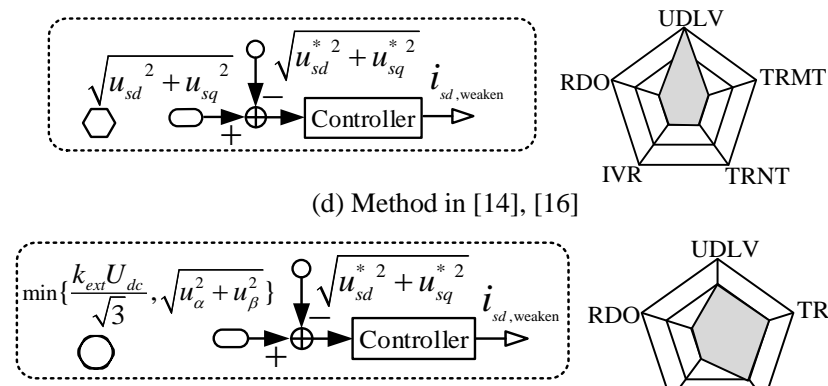

(e) Method in [19]
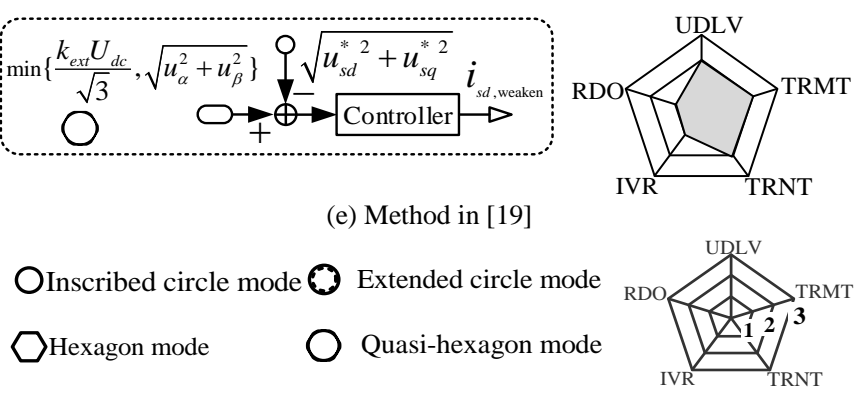

Fig. 2. Block diagram and performance evaluation pentagon of VCFS and VCFS-based schemes.

\section{ANALYSIS ON TORQUE PERFORMANCE IMPROVEMENT UNDER DIFFERENT CONDITIONS}




\section{IEEE POWER ELECTRONICS REGULAR PAPER/LETTER/CORRESPONDENCE}

\section{A. Torque Ripple Analysis under DC-Link Overvoltage}

When IM operates in the high-speed region to further extend the utilization of DC-Link voltage, since $u_{\text {smax }}$ becomes variable, the circumstance is much more complicated than that shown in Fig. 1. Fig. 3 describes the possible voltage vector trajectory at a certain high-speed operating condition $\omega_{e}^{*}[19]$. It can be seen that the operating point can migrate randomly at any points on segment $\mathrm{A}-\mathrm{B}$, causing the torque ripple.

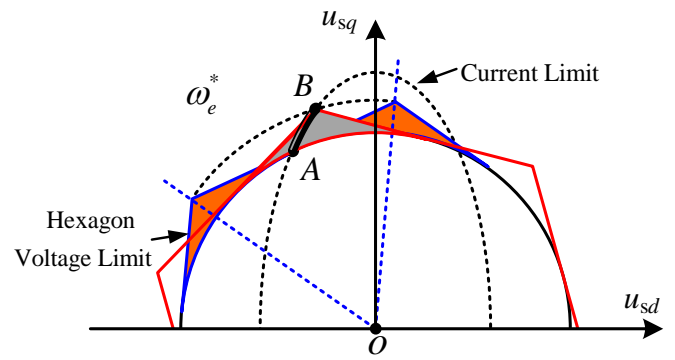

Fig. 3. Possible operating points at a certain operating time.

Since the maximum torque ripple point always locates at the intersection of the hexagon and the current limit, the relationship between the maximum torque ripple point and the DC-Link voltage at different frequencies can be expressed as (3), and the detailed derivation is shown in Appendix A.

Despite that solution to DC-Link overvoltage has been investigated for the inscribed circle mode in [20], studies for voltage extension mode, where overvoltage influence on system becomes severer, is still not clear. It is known that the DC-Link overvoltage usually happens due to the energy feedback during brake, and the case is more obvious when the IM sharply decelerates from a high speed. Assuming that the overvoltage of DC-Link is $130 \%$ (the protection threshold value often set in commercial inverters), Fig. 4(a) shows the maximum torque change of inscribed circle mode $(m=1 / \sqrt{3})$ and hexagon mode $(m=2 / 3)$ in high-speed region (frequency varies from $150 \mathrm{~Hz}$ to $250 \mathrm{~Hz}$ ) with DC-Link voltage increasing from $100 \%(537 \mathrm{~V})$ to $130 \%(707 \mathrm{~V})$ respectively. Fig. 4(b) further shows the corresponding changes of torque ripple (absolute values $T_{\text {eripple }}$ (4) and percentage values $T_{e, r}$ $(5))$.

$$
\begin{gathered}
T_{e, \text { ripple }}=\left(T_{e_{-} \text {hex }}-T_{e_{-} \text {insc }}\right) \\
T_{e, \text { ripple_percent }}=\left(T_{e_{-} \text {hex }}-T_{e_{-} \text {inss }}\right) / T_{e_{-} \text {inss }} * 100 \%
\end{gathered}
$$

where $T_{e_{-} h e x}=T_{e}\left(1 / \sqrt{3}, \omega_{e}, U_{d c}\right), T_{e_{-} \text {insc }}=T_{e}\left(2 / 3, \omega_{e}, U_{d c}\right)$.

From Fig. 4, the following phenomena are of particular interest:

1) No matter in the inscribed circle mode or in the hexagon mode, the variation of torque (maximum torque or torque ripple) absolute values caused by the change of DC-Link voltage become severe as $\omega_{e}$ increases.

$$
T_{e}\left(m, \omega_{e}, U_{d c}\right)=\frac{3 n_{p} L_{m}^{2}\left((1+\sigma) R_{s} \omega_{e} L_{s} \sigma\left(m^{2} U_{d c}^{2}-\omega_{e} L_{s}^{2} i_{s \max }^{2}\right)+\left(R_{s}^{2}-\omega_{e}^{2} \sigma L_{s}^{2}\right) \sqrt{\left(-\sigma^{2} m^{2} U_{d c}^{2}+\omega_{e} \sigma L_{s}^{2} i_{s \max }^{2}\right)\left(m^{2} U_{d c}^{2}-\omega_{e} \sigma L_{s}^{2} i_{s \max }^{2}\right)}\right)}{2 L_{r}\left(1-\sigma^{2}\right)\left(R_{s}+\omega_{e}^{2} \sigma L_{s}^{2}\right)^{2}}
$$

2) From the percentage value of torque ripple shown in Fig.4 (b), the higher DC-Link voltage always shows a better tolerance to torque ripple in the hexagon mode at a certain $\omega_{e}$.

3) From Fig. 4 (a), 130\% DC-Link overvoltage results in more than $30 \%$ torque ripple in the hexagon mode. Further adding 15\% 20\% intrinsic torque ripple of hexagon operation itself shown in Fig. 4 (b), the total torque ripple will be nearly $50 \%$ at high-speed region.

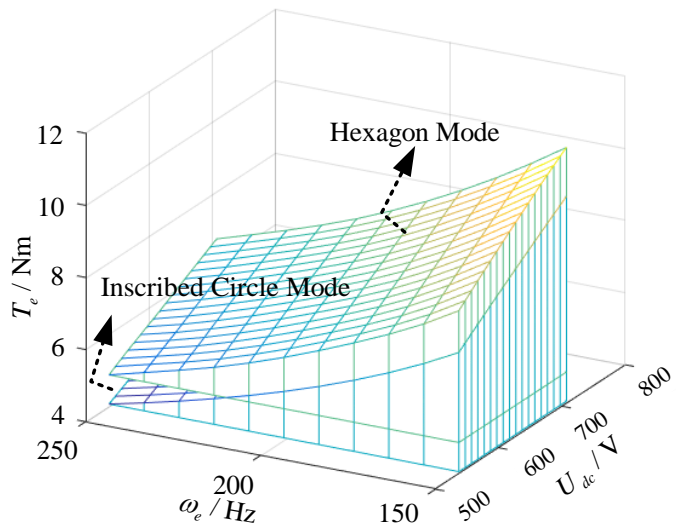

(a)

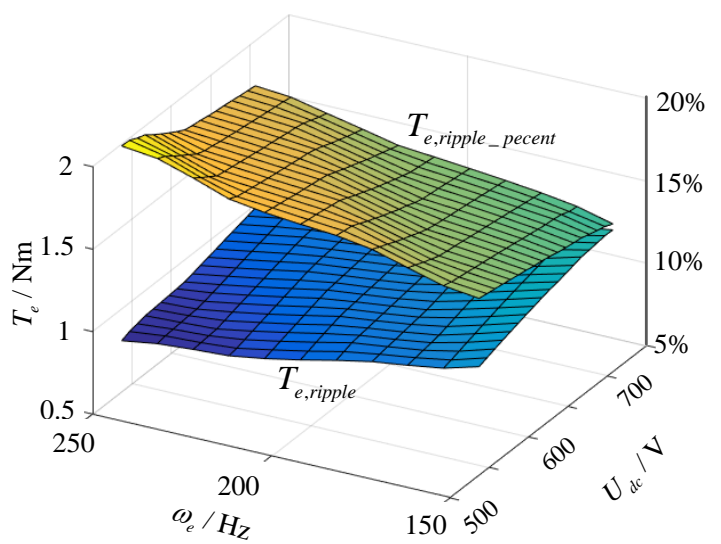

(b)

Fig. 4. Maximum torque and torque ripple trend at varying frequencies with increasing DC-Link voltage. (a) In the inscribed circle mode and the hexagon mode. (b) Absolute and percentage values of torque ripple.

It can be concluded that the hexagon operation for fluxweakening control shows much weaker robustness to DC-Link overvoltage, which is a serious problem resulting in deteriorated system performance or even instability. Therefore, even though the DC-Link overvoltage caused by the feedback energy is inevitable and cannot be directly controlled by the flux-weakening methods, it still will be a progressive improvement for system stability if the fluctuated DC-Link voltage is thoroughly removed from the control loop, especially for high-speed operation in voltage extension region. 


\section{IEEE POWER ELECTRONICS REGULAR PAPER/LETTER/CORRESPONDENCE}

\section{B. Torque Ripple Alleviation in Non-maximum Torque Conditions}

In high-speed region, since the quasi-hexagon or hexagon voltage limit is used for IM closed-loop flux-weakening control, the operating point always moves along the fluctuated voltage boundary, resulting in undesirable torque ripple regardless of load conditions. As shown in Fig. 5, with the reduction of load torque from $T_{1}$ (maximum torque) to $T_{2}$ (non-maximum torque), the operating point $\mathrm{O}$ will possibly move along the red curve, and keep varying between Point $\mathrm{A}$ and Point B in steady state. Considering that the maximum torque control is only needed in some cases such as step acceleration/deceleration and full-load operation, torque ripple can be averted by adjusting the operating point in nonmaximum torque control. For example, Point $\mathrm{C}$ has been proved as a proper point for dynamic torque response with additional control strategy to ensure a constant flux [12]; Point $\mathrm{D}$ ensures a well eliminated torque ripple but the rapid shrink of $d-q$ axis voltages possibly brings about dynamic problems; Point B can be easily achieved by adjusting the voltage reference in flux-weakening controller. The detailed operating point selection can be further determined by considering minimum current amplitude, or other requirements.

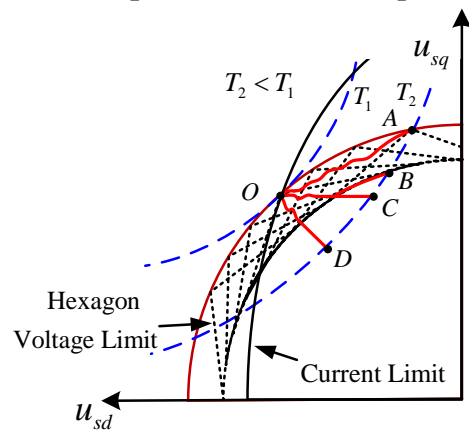

Fig. 5. Operating points selection under load torque variation conditions

\section{Ideal Maximum Torque Point for Deep Flux-weakening Region}

As the operating frequency increases into the deep fluxweakening region (constant voltage region [22]), the maximum torque shrinks in the form of quadratic inverse proportional function. This part is to addresses the exact effect of the stator resistance on the maximum torque.

In previous study, $\alpha=3 \pi / 4$ is derived as the proper maximum torque point. Here, define the torque difference as:

$$
\Delta T_{e}(\alpha)=\left(T_{e_{-} R_{s}}-T_{e_{-} R_{s} n e g}\right) / T_{e_{-} R_{s} \text { neg }} * 100 \%
$$

where $T_{e_{-} R_{s}}$ and $T_{e_{-} R_{s} n e g}$ are the torque considering and neglecting the stator resistance effect respectively, and the detailed derivation of $T_{e_{-} R_{s}}$ and $T_{e_{-} R_{s} \text { neg }}$ are shown in Appendix B (a).

From Fig. 6 (a), although the torque difference is subtle with the decreasing maximum output torque, it cannot be neglected due to its increasing proportion to the operating frequency. Since the output torque is inversely proportional to the operating frequency before entering the deep flux- weakening region, it is shown in Fig. 6(a) that when the operating point migrates to point B (see Fig. 1), the neglected torque is about $4.18 \%$ of the real torque. In Fig. 6(b), the red curve depicts the $d$-axis voltage with respect to $\alpha$ at different operating points in inscribed circle mode. And the blue curve describes the $d$-axis voltage corresponding to the maximum torque point on the tangent with the same operating points as the tangent points. The expression of $u_{\text {sd_circle }}$ and $u_{\text {sd_tangent }}$ are shown in Appendix B (b). Therefore, the intersection point can accurately represent the coincidence between the operation point and the optimal maximum torque point for deep fluxweakening operation. Thus Fig. 6(b) indicates that the setting point B $(\alpha=0.75 \pi)$ does not strictly correspond with the maximum output torque point, and instead, the ideal maximum torque point is advanced at $\alpha=0.7425 \pi$, where $u_{s d}=-214 \mathrm{~V}\left(\right.$ signed as $\left.u_{T M}\right)$.

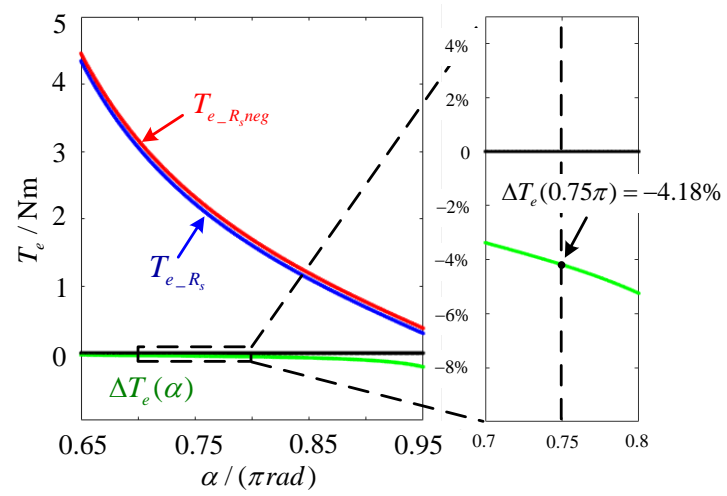

(a)

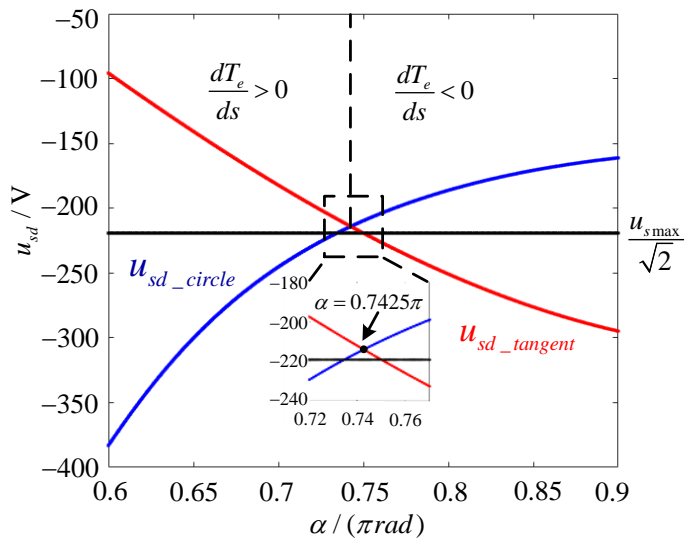

(b)

Fig. 6. Maximum torque point modification in deep flux-weakening region. (a) Torque difference varying with $\alpha$ with (without) considering the stator resistance effect. (b) Searching for ideal maximum torque point.

\section{Proposed FluX-WEAKENING CONTROL METHOD}

In light of the analysis above, this part proposes an optimized flux-weakening control scheme whose performance evaluation of 5 indexes is shown in the blue dashed rectangle in Fig. 7. Compared with previous schemes in Fig. 2, the proposed scheme holds the following novel features:

1) A directly constructed voltage reference with enhanced robustness to DC-Link overvoltage; 


\section{IEEE POWER ELECTRONICS REGULAR PAPER/LETTER/CORRESPONDENCE}

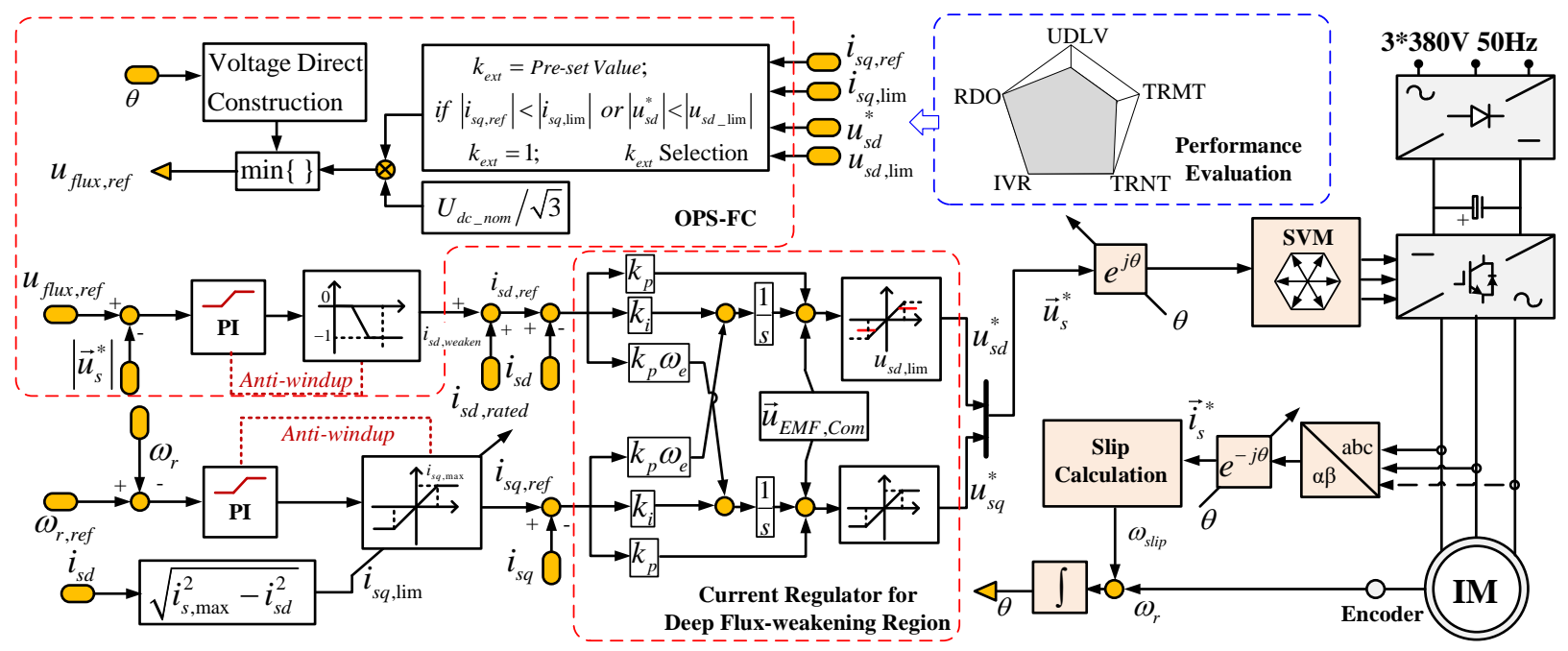

Fig. 7. Block diagram of the proposed flux-weakening scheme.

2) Capability of output torque maximization during the entire wide-speed range along with more concise algorithm;

3) Better torque ripple alleviation during step acceleration/ deceleration and load change conditions.

The proposed scheme mainly consists of two novel parts, which are marked by two red dashed rectangles in Fig. 7. The first part is an OPS-FC, which contains a voltage direct construction block to generate an ideal hexagon voltage reference, and a pre-set coefficient $\left(k_{e x t}\right)$ selection block for mode switch. The second part is a specially modified current regulator for closed-loop operation in the deep flux-weakening region.

\section{A. $O P S-F C$}

In the OPS-FC, voltage reference is constructed in a direct way rather than using the reconstructed voltage to achieve accuracy flux-weakening control and anti-disturbance rejection capability. Due to the influence of the switching time and the DC-Link voltage fluctuation, the reconstructed voltage and the command voltage are similar, but not the same. Within the base speed region, the disparity may be accumulated by the integrate part in flux-weakening controller and exert an undesirable interruption on $d$-axis current reference. For the flux-weakening region, when DC-Link overvoltage occurs, the influenced reconstructed voltage employed in both flux-weakening controller and current loop anti-windup block will inevitably deteriorate the system robustness.

As for the direct construction, an ideal hexagon is first required. In the two phase stationary reference frame, $d-q$ axis and the command voltage vector are rotating and maintaining the relative position shown in Fig. 1. It is important to ensure the phase consistency of reference and feedback voltage vector, so that the feedback voltage vector can always follow the reference to slide alongside the hexagon boundary, as shown in Fig. 8.

The hexagon voltage reference $u_{\text {hex, ref }}$ in OPS-FC is constructed as

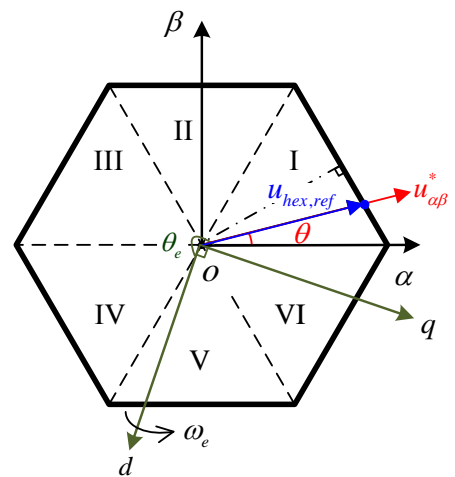

Fig. 8. Formation of the ideal hexagon voltage reference.

$$
u_{\text {hex,ref }}=\left\{\begin{array}{l}
\text { Sec.I: } \frac{U_{d c_{-} \min }}{\sqrt{3}} /\left(\frac{\sqrt{3}}{2} \cos \theta+\frac{1}{2} \sin \theta\right) \\
\text { Sec.II: } \frac{U_{d c_{-} \min }}{\sqrt{3}} / \sin \theta \\
\text { Sec.III: } \frac{U_{d c_{-} \min }}{\sqrt{3}} /\left(-\frac{\sqrt{3}}{2} \cos \theta+\frac{1}{2} \sin \theta\right) \\
\operatorname{Sec} . \mathrm{IV}: \frac{U_{d c_{-} \min }}{\sqrt{3}} /\left(-\frac{\sqrt{3}}{2} \cos \theta-\frac{1}{2} \sin \theta\right) \\
\operatorname{Sec} . \mathrm{V}:-\frac{U_{d c_{-} \min }}{\sqrt{3}} / \sin \theta \\
\operatorname{Sec} . \mathrm{VI}: \frac{U_{d c_{-} \min }}{\sqrt{3}} /\left(\frac{\sqrt{3}}{2} \cos \theta-\frac{1}{2} \sin \theta\right)
\end{array}\right.
$$

where:

$U_{d c_{\_} \text {min }}=\min \left\{U_{d c,} U_{d c_{-} n o m}\right\} ; \sin \theta=\frac{u_{\beta}^{*}}{\sqrt{u_{\alpha}^{* 2}+u_{\beta}^{* 2}}} ; \cos \theta=\frac{u_{\alpha}^{*}}{\sqrt{u_{\alpha}^{* 2}+u_{\beta}^{* 2}}}$.

Here, if the real value $U_{d c}$ is detected more than the nominal value $U_{d c_{-} n o m}, U_{d c_{-} n o m}$ is applied to remove the interruption of DC-Link overvoltage. Since the entire voltage reference is only related to $\theta$, it is robust and independent with the reconstructed voltage. 

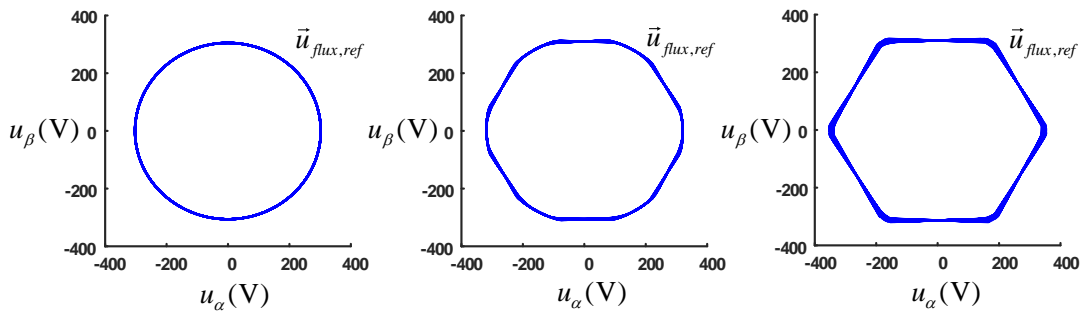

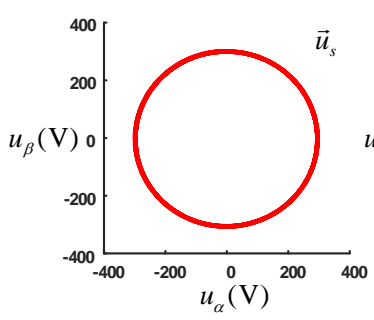

(a)

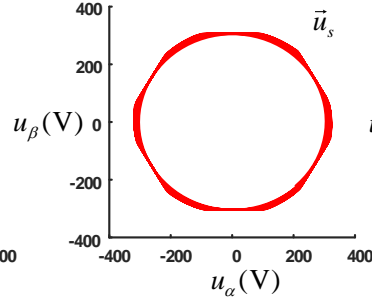

(b)

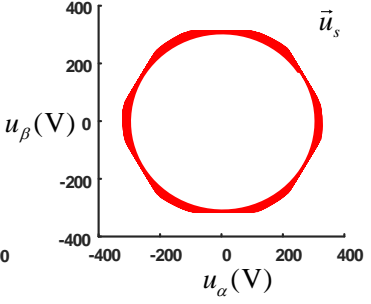

Fig. 9. Simulation results: Voltage reference vectors in flux-weakening controller and voltage vectors produced by SVPWM during high speed operation under various $k_{e x t}$ in $\alpha \beta$ plane. (a) $k_{e x t}=1.00$. (b) $k_{e x t}=1.05$. (c) $k_{e x t}=1.15$.

For step acceleration and full-load conditions, it is required to extend the maximum torque while suppress the intolerable torque ripple. To this end, the initial value of coefficient $k_{e x t}$ is pre-set, and thus the voltage reference is ultimately a quasihexagon with rounded edges which is determined by the minimum value of $k_{\text {ext }} U_{d c_{-} n o m} / \sqrt{3}$ and the ideal hexagon boundary.

To illustrate the effect of different $k_{\text {ext }}$, a ripple assessment in voltage extension region is given by the simulation results, as shown in Figs. 9-10. Here, $k_{\text {ext }}$ in the OPS-FC is set as 1.00, 1.05 and 1.15 , corresponding to the inscribed circle mode (the same as scheme in Fig. 2 (a)), quasi-hexagon mode (the same as scheme in Fig. 2 (e)) and hexagon mode (the same as Schemes in Fig. 2 (c) and Fig. 2 (d)), respectively. Fig. 9 shows voltage vectors of flux-weakening control during step acceleration period in $\alpha \beta$ domain. It can be seen that larger $k_{\text {ext }}$ corresponds to higher DC-Link voltage utilization, and as the increase of the DC-Link voltage utilization, the voltage vector produced by SVPWM tends to be a hexagon. Fig. 10 shows the system response of step speed command with different $k_{\text {ext }}$. It can be seen that despite of the improvement of DC-Link voltage utilization, the inevitable torque ripple (indicated from $d q$ axis currents) is synchronously severer. Therefore, in fact, $k_{e x t}$ is a tradeoff coefficient of operating mode selection between output torque amplitude and ripple for maximum output torque conditions.

Unlike the maximum output torque conditions, the operating point of non-maximum output torque conditions should be manipulated to shrink away from the voltage extension region for torque ripple alleviation by setting $k_{e x t}=1$ (corresponding to point B in Fig. 5). Besides, as shown in " $k_{e x t}$ Selection" block in Fig. 7, the error of $q$-axis current limit and reference and the error of $d$-axis voltage limit and reference are combined as the judgment for the entire speed range, where the latter one naturally works for deep flux-weakening region and the former one is for the other regions.
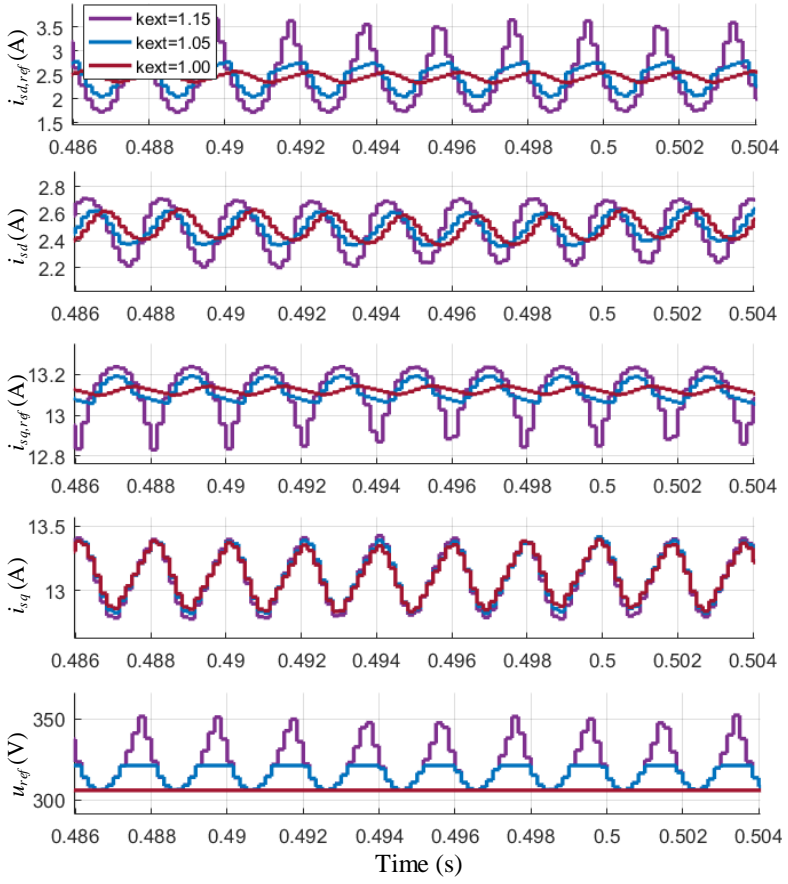

Fig. 10. Simulation results: $d-q$ axis current references and responses and voltage references of speed step command under different $k_{\text {ext }}$.

\section{B. Modified Current Regulator Design}

In the existing researches, the feedforward [29] or complex vector compensations [30] are applied for current regulator decoupling and additional PI regulator is employed to modify the $q$-axis current limit for closed-loop control in deep fluxweakening region. These two parts are always considered separately. However, the additional PI regulator not only complicates the control algorithm, but also increases the tuning difficulty. To address this problem, a commonly used complex vector current regulator with a specially set $d$-axis voltage limit is presented. And the value of $d$-axis voltage 


\section{IEEE POWER ELECTRONICS REGULAR PAPER/LETTER/CORRESPONDENCE}

limit is set as $u_{T M}$ to extract the maximum output torque. Its main contribution is that the existing decoupling path of $d$-axis current regulator is employed as the flux-weakening path for closed-loop control, which averts the additional algorithm. The algorithm feasibility is analyzed in the following part.

The IM voltage equation for complex vector current regulator design is expressed as [29]:

$$
\left\{\begin{array}{l}
u_{s d}=\left(R_{s}^{\prime}+\sigma L_{s} s\right) i_{s d}-\sigma L_{s} \omega_{e} i_{s q}-\frac{L_{m} R_{r}}{L_{r}^{2}} \lambda_{r} \\
u_{s q}=\left(R_{s}^{\prime}+\sigma L_{s} s\right) i_{s q}+\sigma L_{s} \omega_{e} i_{s d}+\frac{L_{m} \omega_{r}}{L_{r}} \lambda_{r}
\end{array}\right.
$$

where : $R_{s}^{\prime}=R_{s}+R_{r}\left(L_{m} / L_{r}\right)^{2}, s$ is the differential operator.

According to (8), the complex vector current regulator shown in Fig. 7 is given by

$$
\left\{\begin{array}{l}
u_{s d}^{*}=\left(k_{p}+\frac{k_{i}}{s}\right)\left(i_{s d, r e f}-i_{s d}\right)-\frac{k_{p} \omega_{e}}{s}\left(i_{s q, r e f}-i_{s q}\right)+u_{s d-E M F, \text { Com }} \\
u_{s q}^{*}=\left(k_{p}+\frac{k_{i}}{s}\right)\left(i_{s q, r e f}-i_{s q}\right)+\frac{k_{p} \omega_{e}}{s}\left(i_{s d, r e f}-i_{s d}\right)+u_{s q-E M F, \text { Com }}
\end{array}\right.
$$

where $k_{p}$ and $k_{i}$ are the proportional gain and the integral gain, satisfying $k_{p}=\sigma L_{s} \omega_{c b}^{*}$ and $k_{i}=R_{s}^{\prime} \omega_{c b}^{*}\left(\omega_{c b}^{*}\right.$ is the expected bandwidth). $u_{s d-E M F, C o m}$ and $u_{s q-E M F, C o m}$ are the Back EMF compensation parts.

And the flux-weakening controller can be written as [19], [20]

$$
i_{s d, \text { ref }}=\Delta u_{s}\left(k_{f p}+k_{f i} / s\right)+i_{s d, \text { rated }}
$$

where $\Delta u_{s}=\sqrt{u_{s d}^{2}+u_{s q}^{2}}-\sqrt{u_{s d}^{* 2}+u_{s q}^{* 2}} ; k_{f p}$ and $k_{f i}$ are the proportional gain and the integral gain of PI in the fluxweakening controller.

Considering that the maximum value of $u_{s d}$ is clamped to $u_{T M}$ in the deep flux-weakening region, $\Delta u_{s q}$ is the de facto dynamic part of $\Delta u$ for the flux-weakening adjustment. Thus, $\Delta u_{s}$ can be replaced by $\Delta u_{s q}$ and the flux-weakening controller can be rewritten as

$$
i_{s d, r e f}=\left(u_{s q}-u_{s q}^{*}\right)\left(k_{f p}+k_{f i} / s\right)+i_{s d, \text { rated }}
$$

Assuming that the Back EMF part $\vec{u}_{E M F, C o m}$ is completely compensated, the flux-weakening path can be finally expressed as (12).

When the IM speed increases into the deep flux-weakening region, $u_{s d}$ tends up to $u_{T M}$, and thus $i_{s q}$ cannot follow its reference set as $\sqrt{i_{s, \text { max }}^{2}-i_{s d}^{2}}$. Note that, there is no extra switchover process for the $i_{s q, \text { ref }}$ limit in the proposed method. The decreasing $i_{s q}$ is naturally forced by the limited $u_{s d}$ instead of following $i_{s q, \text { ref }}$ manipulated by additional algorithms shown in [12], [22]. Since the $q$-axis current regulator is not in the limit state, the error between $i_{s q, r e f}$ and $i_{s q}$ keeps accumulating resulting in the increase of $u_{s q}^{*}$. The negative error between $u_{s q}^{*}$ and $u_{s q}$ caused by over-modulation generates an extra item to weaken $i_{s d, r e f}$. Due to the saturation of $d$-axis current regulator, the decoupling path $k_{p} \omega_{e}\left(i_{s d, r e f}-i_{s d}\right) / s$ is applied to deliver the $d$-axis current error to $u_{s q}^{*}$, and thus the single closed loop for flux-weakening control is formed in deep fluxweakening region. In this case, the clamped $d$-axis voltage is applied for the maximum output torque capability, while the $q$-axis voltage is for the dynamic adjustment. Once the acceleration period ends, the system will turn back to the initial state.

In Fig. 11, a step speed command from $0 \mathrm{rpm}$ to $4500 \mathrm{rpm}$ is given, and then another step speed command from 4500rpm to 9000rpm (to ensure deep flux-weakening operation) is given at $1.0 \mathrm{~s}$ (1500rpm is the base speed). The red waveforms are the speed and current responses of the proposed method, while the blue waveforms are that of the conventional method presented in [12]. It can be seen that although the additional PI regulator is removed, the proposed method can still guarantee the stable operation and almost the same dynamic performance as the conventional method (with a well-tuned PI regulator) during the entire speed range. And meanwhile, since $u_{s d}$ is set at a more proper value in the deep fluxweakening region, the enhanced maximum torque can achieve $2.4 \%$ improvement of acceleration time with a smaller stator current, which matches the theoretical analysis well. This superiority will be more obvious if a deeper flux-weakening operation is required.

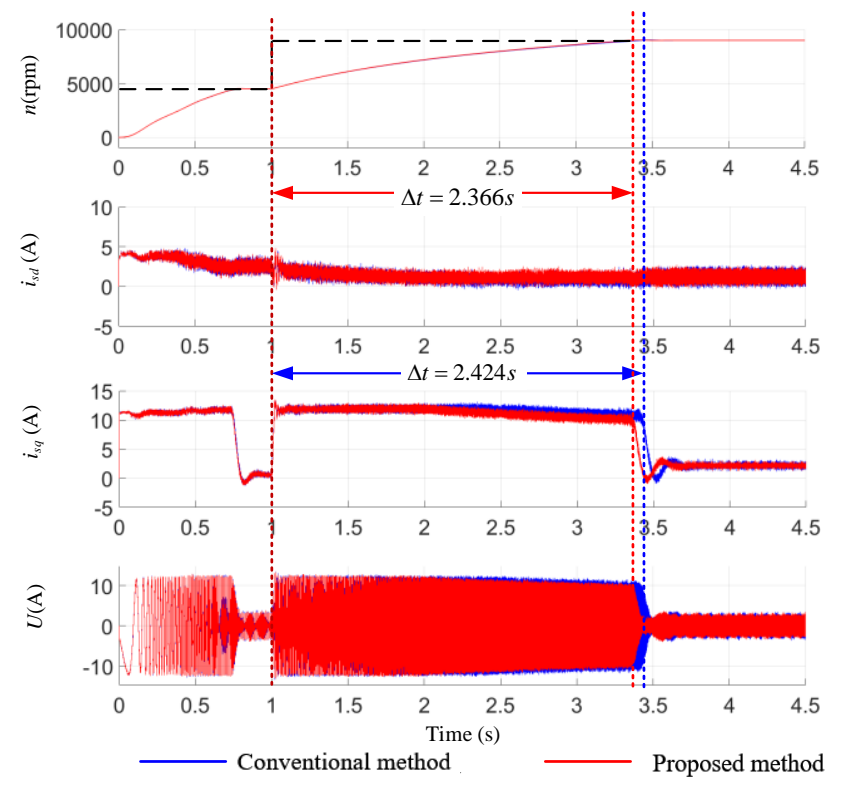

Fig. 11. Simulation Results: Comparison of speed and current responses of step accelerations from 0rpm to 4500rpm and then to 9000rpm between proposed method and the conventional method presented in [12].

$$
i_{s d, r e f}=\left[\left(R_{s}^{\prime}+\sigma L_{s} s\right) i_{s q}+\sigma L_{s} \omega_{e} i_{s d}-\left(k_{p}+\frac{k_{i}}{s}\right)\left(i_{s q, r e f}-i_{s q}\right)-\frac{k_{p} \omega_{e}}{s}\left(i_{s d, r e f}-i_{s d}\right)\right]\left(k_{f p}+\frac{k_{f i}}{s}\right)+i_{s d, \text { rated }}
$$




\section{Parameter Sensitivity Discussion}

In the OPS-FC, the voltage and current information used has no strict relationship with motor parameters, and the PI coefficients are selected by experimental trial-and-error method (stability proof and selection criteria can be found in [19], [20]), meaning that it is narrowly dependent on motor parameters. Besides, in the voltage direct construction block, the voltage reference is only related to $\theta$ and the accuracy can be guaranteed by the zero-phase-error over modulation strategy [28] if the field-oriented angle in IFOC is well controlled. Regarding to the modified complex vector current regulator, [30] has proved that it shows the decreased parameter sensitivity compared with traditional PI current regulator with cross-coupling part. Hence, we can conclude that the proposed scheme retains the parameter robustness during the whole speed range. But it is worth mentioning that since it is an IFOC-based scheme, the parameter sensitivity problem that exists in IFOC system is still inevitable.

\section{EXPERIMENTAL RESULTS}

An experimental setup consisting of IGBT-based inverters and $3.7 \mathrm{~kW} 3$-phase squirrel-cage IMs has been built to verify the feasibility of proposed algorithm. Parameters of the IM are shown in Table. I, and the setup permits a safe operation at maximum speed of $9000 \mathrm{rpm}$ (6 p.u., and 1 p.u. is $1500 \mathrm{rpm}$ ). The entire IFOC-based control system is shown in Fig. 7, where the PWM switching frequency is $f_{P W M}=6 \mathrm{kHz}$; $k_{f p}=0.02, k_{f i}=0.2$; and $k_{p}=10.14, k_{i}=1753.48\left(\omega_{c b}^{*}=150 \mathrm{~Hz}\right)$. TABLE I

PARAMETERS OF THE INDUCTION MACHINE

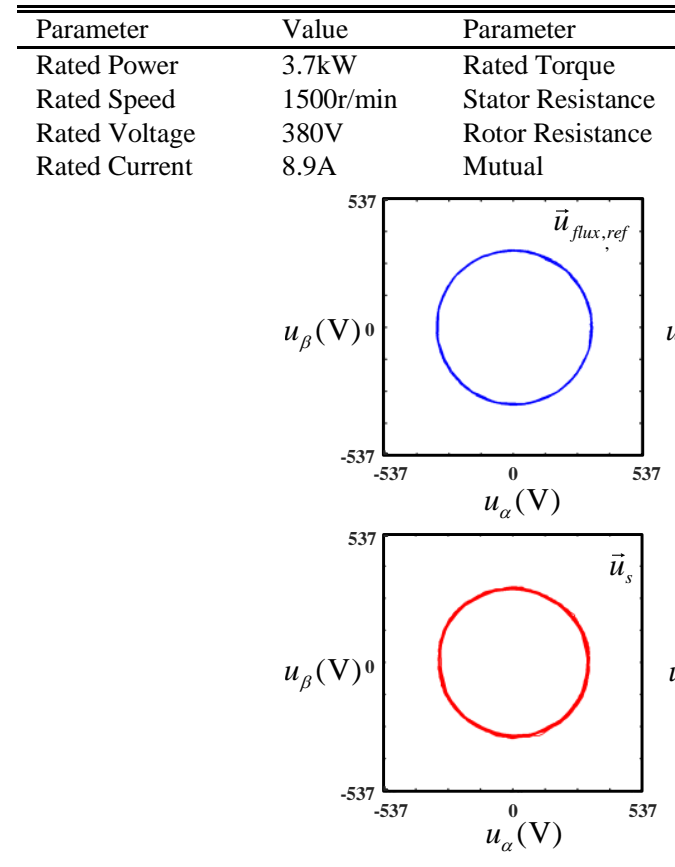

(a)

Value

$23.6 \mathrm{~N} \cdot \mathrm{m}$

$23.6 \mathrm{~N} \cdot \mathrm{m}$

$118.9 \mathrm{mH}$

\begin{tabular}{llll} 
& & Inductance \\
Rated frequency & $50 \mathrm{~Hz}$ & Stator Inductance & $124.4 \mathrm{mH}$ \\
Inertia & $0.0123 \mathrm{~kg} \cdot \mathrm{m}^{2}$ & Rotor Inductance & $124.4 \mathrm{mH}$ \\
\hline \hline
\end{tabular}

\section{A. DC-Link Voltage Utilization Under Different Pre-set $k_{\text {ext }}$}

Fig. 12 shows voltage vectors under different pre-set $k_{\text {ext }}$ values. Experimental conditions are the same as that in Fig. 9. It can be seen that as $k_{\text {ext }}$ increases, the reference (blue curves) and the feedback (red curves) voltage vectors have the same tendency to be a hexagon. Thus, the experimental results and simulation results (see Fig. 9) can achieve a good consistency.

\section{B. Deep Flux-Weakening Operation up to Wide Speed Range}

To verify the feasibility of the deep flux-weakening operation, a step speed command of 6 p.u. (9000 rpm) is given from 3 p.u. (4500rpm). The waveforms of motor speed, $d q$ axis current, and phase current are shown in Fig. 13, respectively. When operating at 3 p.u., the IM is still constrained by the maximum voltage with insufficient voltage margin. Once the sudden speed happens, the voltage change from $q$-axis current regulator will affect $d$-axis current through flux-weakening controller. To realize the wide speed range operation from 1 p.u. to 6 p.u., the tuning of PI regulator in flux-weakening controller needs to seek a balance between the stability and rapidity. Hence, for step change under high-speed operation, a period of time is required to adjust and make sure that the stator voltage can refollow the maximum voltage boundary. It can be seen that after a short period of oscillation, a smooth and stable speed acceleration is achieved with the proposed method. As the motor speed increases into the deep flux-weakening region, the $q$-axis current starts to reduce, and thus the phase current shrinks correspondingly. Due to the high-speed operation, the flux is weaken deeply (indicated from $d$-axis current) to ensure the capability of speed increase.

\section{Torque Ripple Alleviation under Load Change Conditions}




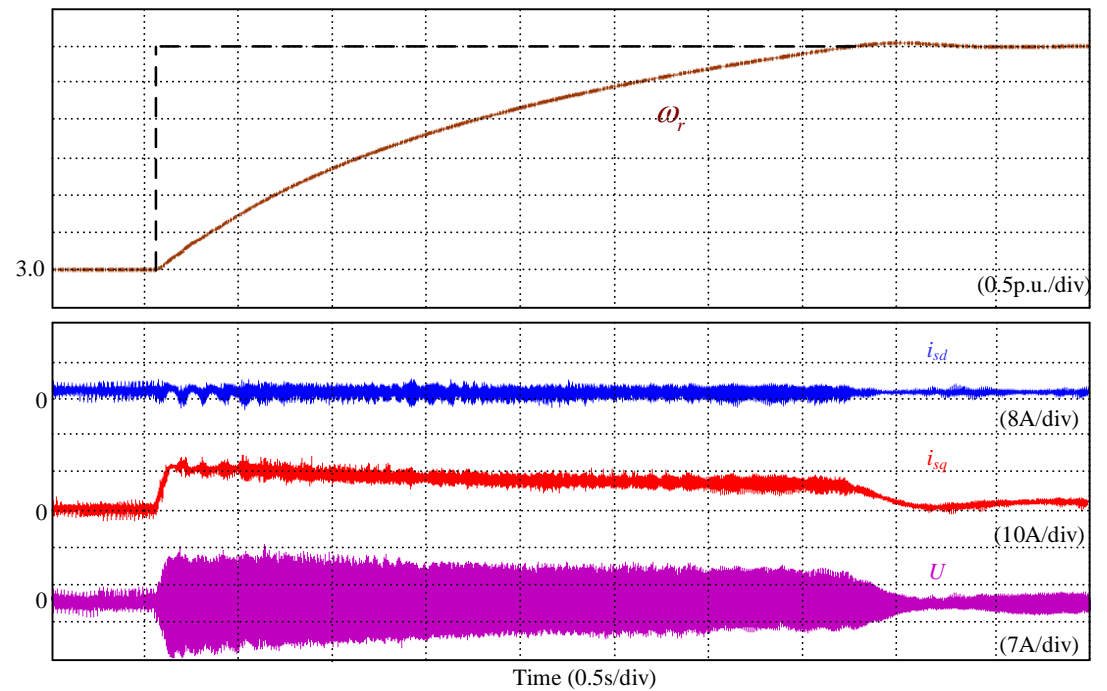

Fig. 13. Speed and current responses of a step acceleration from 3p.u. to 6p.u.

To certify the effectiveness of operating point selection in the proposed method, the comparison experiments are conducted under load torque change conditions. As shown in Fig. 14, a step speed command from 0 p.u. to 3 p.u. (4500rpm) is first given, and then the system returns to the steady state after a short acceleration time. After that, a step change of $10 \%$ rated load each time is given until the system tends to be unstable.

Note that Fig. 14 (a) and (b) are carried out under the same conditions except that the operation point selection block is

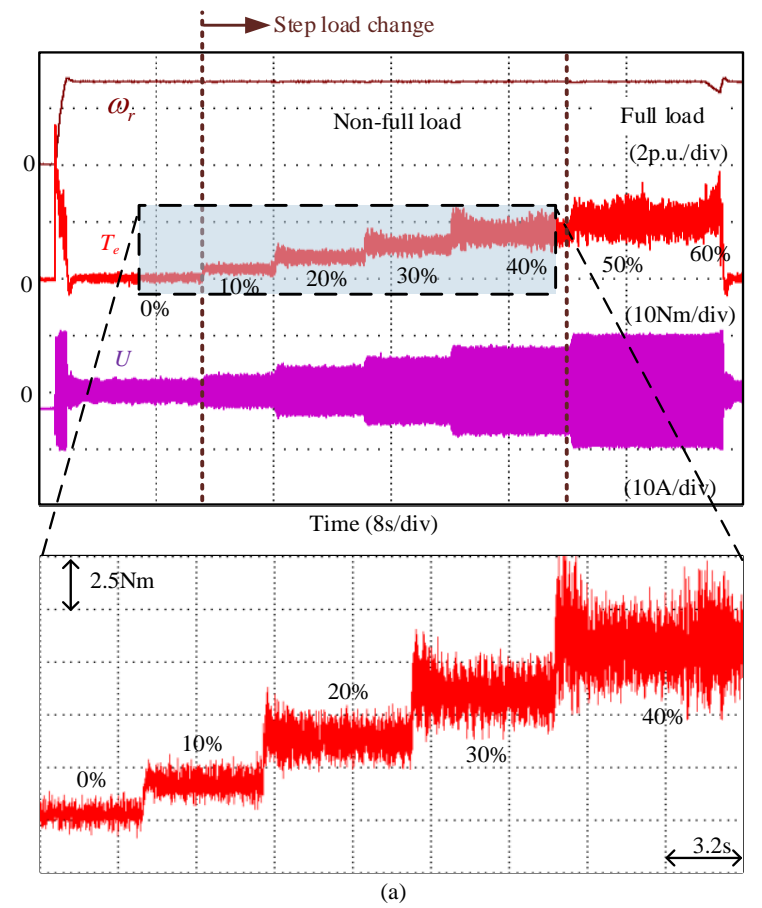

Fig. 14. Comparison of torque response under load change conditions at 3 p.u. (4500rpm) (a) without operating point selection. (b) with operating point selection. omitted in Fig. 14 (a). Therefore, we can see that during the step acceleration period and the full load period, performances in Fig. 14 (a) and Fig. 14 (b) are the same, indicating the maximum output torque capability of the system. In contrast, it can be evidently seen from the enlarged parts that, under the same non-full load conditions from $0 \%$ to $40 \%$, the torque response in Fig. 14 (a) suffers from severer ripple, while the ripple is obviously mitigated in Fig. 14 (b). Hence, with the operating point selection, torque ripple alleviation is obtained.

\section{DC-Link Overvoltage Rejection}

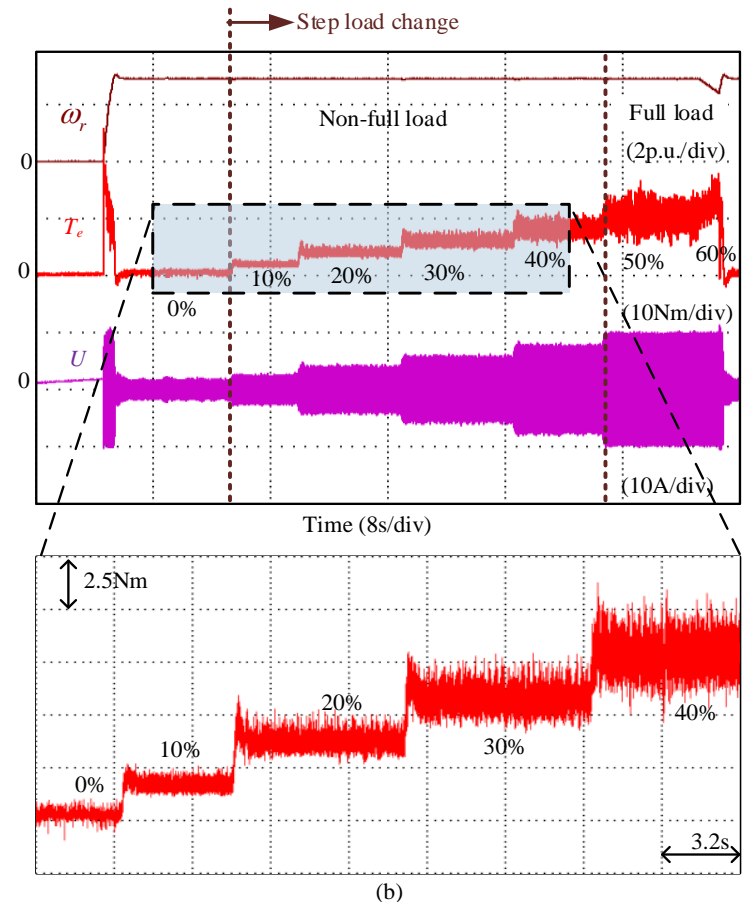




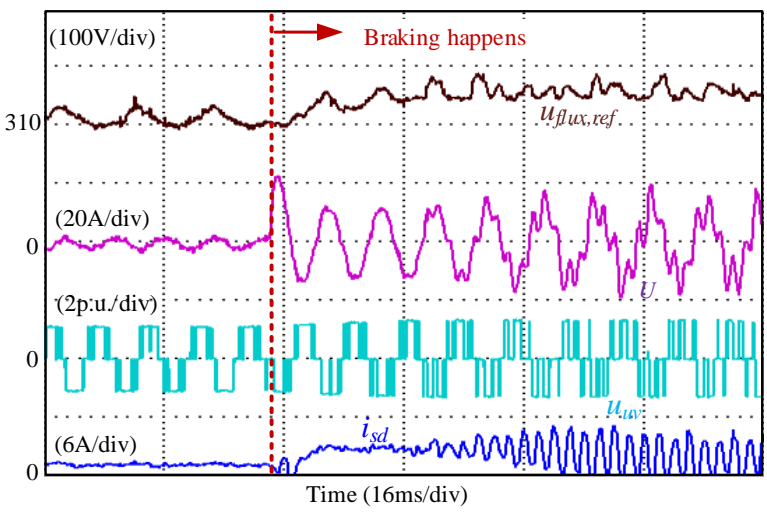

(a)

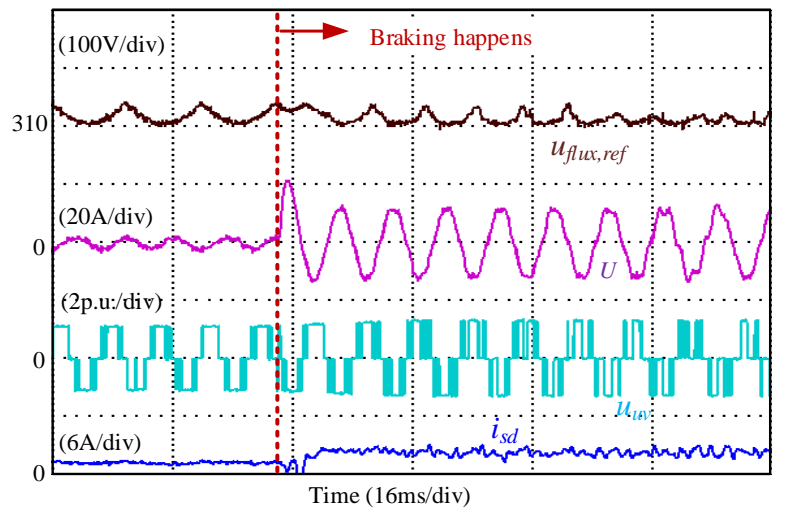

(b)

Fig. 15. Comparison of current response under DC-Link overvoltage. (a) without overvoltage rejection. (b) with overvoltage rejection.

To test the overvoltage rejection performance of the proposed method, the braking operation experiments are conducted with a step deceleration from 3 p.u. (4500 rpm) to 0 rpm. The reconstructed voltage is used in Fig.15 (a), while the proposed method with voltage reference directly constructed is used in Fig.15 (b). The instantaneous increase of DC-Link voltage is caused by the sudden energy feedback, and the waveform of terminal voltage indicates that the IM operations in quasi-hexagon mode. It can be seen that the proposed method can achieve smoother phase current and more stable $d$ axis current response.

\section{CONCLUSIONS}

This paper presents a systematic optimization of fluxweakening control for induction motor under multiple working conditions. Two crucial and interesting points, the degeneration of system stability resulting from DC-Link overvoltage and the precise maximum torque point in deep flux-weakening region, are detailed discussed. The rejection of DC-Link overvoltage, the tradeoff of torque maximization and torque ripple suppression, and torque improvement for different occasions are achieved and integrated in an OPS flux-weakening controller. Furthermore, the flux-weakening control and the current loop are investigated integrally. The proposed structure with a shared feedback path effectively simplifies the algorithm and eliminates the complexity of parameter tuning in deep flux-weakening region. Verification on the superiority of proposed scheme has been taken on by simulation and experiment on a commercial $3.7 \mathrm{~kW}$ platform. The future work will focus on the operating point selection in high-speed occasions considering energy-consuming optimization.

\section{APPENDIX A}

The following is the derivation of the relationship between torque and DC-Link voltage.

Considering the effect of different modes, voltage limit and current limit are expressed as

$$
\left\{\begin{array}{l}
u_{s d}^{2}+u_{s q}^{2}=m^{2} U_{d c}^{2} \\
\frac{u_{s d}^{2}}{\left(\omega_{e} \sigma L_{s}\right)^{2}}+\frac{u_{s q}^{2}}{\left(\omega_{e} L_{s}\right)^{2}}=i_{s \max }^{2}
\end{array}\right.
$$

where the value of $m$ is determined by modulation strategies. And the equation of $u_{s d}$ and $u_{s q}$ expressed by $U_{d c}$ is

$$
\left\{\begin{array}{l}
u_{s d}=\sqrt{\frac{-\sigma^{2} m^{2} U_{d c}^{2}+\omega_{e} \sigma L_{s}^{2} i_{s \max }^{2}}{1-\sigma^{2}}} \\
u_{s q}=\sqrt{\frac{m^{2} U_{d c}^{2}-\omega_{e} \sigma L_{s}^{2} i_{s \max }^{2}}{1-\sigma^{2}}}
\end{array}\right.
$$

Torque equation expressed in voltage form [19] is

$$
T_{e}=\frac{3 n_{p} L_{m}^{2}}{2 L_{r}} \frac{\left(R_{s} u_{s d}+\omega_{e} \sigma L_{s} u_{s q}\right)\left(R_{s} u_{s q}-\omega_{e} L_{s} u_{s d}\right)}{\left(R_{s}+\omega_{e}^{2} \sigma L_{s}^{2}\right)^{2}}
$$

By substituting (14) into (15), we can obtain the equation (3).

\section{APPENDIX B}

In reference [19], considering the stator resistance effect, the torque $T_{e_{-} R_{s}}$ on the tangent of the inscribed circle relating to $u_{s d}$ is expressed as:

$$
T_{e_{-} R_{s}}=G\left(\omega_{e}^{2}\right)\left[-k_{1} k_{2} u_{s d}^{2}+\left(k_{1} b_{2}-k_{2} b_{1}\right) u_{s d}+b_{1} b_{2}\right]
$$

where

$$
G\left(\omega_{e}^{2}\right)=\frac{3 n_{p} L_{m}^{2}}{2 L_{r}\left(R_{s}+\omega_{e}^{2} \sigma L_{s}^{2}\right)^{2}}
$$

$$
\begin{array}{ll}
k_{1}=R_{s}-\frac{\cos \alpha}{\sin \alpha} \omega_{e} \sigma L_{s}, & b_{1}=\omega_{e} \sigma L_{s} \frac{R}{\sin \alpha} . \\
k_{2}=\frac{\cos \alpha}{\sin \alpha} R_{s}+\omega_{e} L_{s}, & b_{2}=\frac{R R_{s}}{\sin \alpha}
\end{array}
$$

A. Expression of $T_{e_{-} R_{s}}$ and $T_{e_{-} R_{s} n e g}$

In the inscribed circle mode, $u_{s d}$ is expressed as:

$$
u_{s d}=U_{d c} \cos \alpha / \sqrt{3}
$$

Then, substituting (17) into (16), the expression of $T_{e_{-} R_{s}}(\alpha)$ is as follows: 


$$
T_{e_{-} R_{s}}=G\left(\omega_{e}^{2}\right)\left[-k_{1}^{\prime} k_{2}^{\prime} \cos \alpha^{2}+\left(k_{1}^{\prime} b_{2}^{\prime}-k_{2}^{\prime} b_{1}^{\prime}\right) \cos \alpha+b_{1}^{\prime} b_{2}^{\prime}\right]
$$

where

$$
\begin{gathered}
G\left(\omega_{e}^{2}\right)=\frac{3 n_{p} L_{m}^{2}}{2 L_{r}\left(R_{s}+\omega_{e}^{2} \sigma L_{s}^{2}\right)^{2}} \\
k_{1}^{\prime}=\frac{U_{d c}}{\sqrt{3}}\left(R_{s}-\frac{\cos \alpha}{\sin \alpha} \omega_{e} \sigma L_{s}\right), \quad b_{1}^{\prime}=\frac{U_{d c} \omega_{e} \sigma L_{s}}{\sqrt{3} \sin \alpha} . \\
k_{2}^{\prime}=\frac{U_{d c}}{\sqrt{3}}\left(\frac{\cos \alpha}{\sin \alpha} R_{s}+\omega_{e} L_{s}\right), \quad b_{2}^{\prime}=\frac{U_{d c} R_{s}}{\sqrt{3} \sin \alpha}
\end{gathered}
$$

Similarly, the expression of $T_{e_{-} R_{s} \text { neg }}(\alpha)$ is:

$$
T_{e_{-} R_{s} \text { neg }}=\frac{3 n_{p} L_{m}^{2} i_{s \max }^{2} \sigma^{2} L_{s}^{2}}{2 \sigma L_{r} L_{s}^{2}} \frac{\cos \alpha \sin \alpha}{\left(\cos ^{2} \alpha+\sigma^{2} \sin ^{2} \alpha\right)}
$$

\section{B. Expression of $u_{\text {sd_circle }}$ and $u_{\text {sd_tangent }}$}

From (17), $T_{e_{-} R_{s}}$ on the tangent is a quadratic function of $u_{s d}$, thus, the maximum torque always locates at the axis of symmetry and expression of $u_{\text {sd_circle }}$ and $u_{\text {sd_tangent }}$ are as follows:

$$
\left\{\begin{array}{l}
u_{\text {sd_circle }}=U_{d c} \cos \alpha / \sqrt{3} \\
u_{\text {sd_tangent }}=\frac{k_{1} b_{2}-k_{2} b_{1}}{2 k_{1} k_{2}}
\end{array}\right.
$$

\section{REFERENCES}

[1] A. Raisemche, M. Boukhnifer, C. Larouci, and D. Diallo, "Two active fault-tolerant control schemes of induction-motor drive in EV or HEV," IEEE Trans. Veh. Technol., vol. 63, no. 1, pp. 19-29, Jan. 2014.

[2] D. Gerada, A. Mebarki, N. L. Brown, K. J. Bradley, and C. Gerada, "Design aspects of high-speed high-power-density laminated-rotor induction machines," IEEE Trans. Ind. Electron., vol. 58, no. 9, pp. 4039-4047, Sep. 2011.

[3] A. Boglietti, P. Ferraris, M. Lazzari, and F. Profumo, "About the design of very high frequency induction motors for spindle applications," in Conf. Rec. IEEE IAS Annu. Meeting, 1992, vol. 1, pp. 25-32.

[4] A. Tenconi, S. Vaschetto, and A. Vigliani, "Electrical machines for high speed applications: design considerations and tradeoffs," IEEE Trans. Ind. Electron., vol. 61, no. 6, pp. 3022-3029, Jun. 2014.

[5] A. Tripathi, A. M. Khambadkone, and S. K. Panda, "Dynamic control of torque in overmodulation and in the field weakening region," IEEE Trans. Power Electron., vol. 21, no. 4, pp. 1091-1098, Jul. 2006.

[6] S. H. Kim and S. K. Sul, "Maximum torque control of an induction machine in the field weakening region," IEEE Trans. Ind. Appl., vol. 31, no. 4, pp. 787-794, Jul./Aug. 1995.

[7] L. Zarri, M. Mengoni, A. Tani, G. Serra, D. Casadei, and J. O. Ojo, "Control schemes for field weakening of induction machines: A review," In Proc. IEEE Workshop Electr. Mach. Design, Control, Diagnosis, 2015, pp. 146-155.

[8] C.-H. Choi, J.-K. Seok, and R. D. Lorenz, "Wide-speed direct torque and flux control for interior PM synchronous motors operating at voltage and current limits," IEEE Trans. Ind. Appl., vol. 49, no. 1, pp. 109-117, Jan./Feb. 2013.

[9] S. H. Kim and J. K. Seok, "Finite-settling steps direct torque and flux control (FSS-DTFC) for torque-controlled interior PM motors at voltage limits," IEEE Trans. Ind. Appl., vol. 50, no. 5, pp. 3374-3381, Sep./Oct. 2014.

[10] S. Kim and J. K. Seok, "Hexagon voltage manipulating control (HVMC) for AC motor drives operating at voltage limit," IEEE Trans. Ind. Appl., vol. 51, no. 5, pp. 3829-3837, Sep./Oct. 2015.
[11] X. Xu and D. W. Novotny, "Selection of the flux reference for induction machine drives in the field weakening region," IEEE Trans. Ind. Appl., vol. 28, no. 6, pp. 1353-1358, Nov./Dec. 1992.

[12] S. H. Kim and S. K. Sul, "Voltage control strategy for maximum torque operation of an induction machine in the field-weakening region," IEEE Trans. Ind. Electron., vol. 44, no. 4, pp. 512-518, Aug. 1997.

[13] L. Harnefors, K. Pietilainen, and L. Gertmar, "Torque-maximizing fieldweakening control: design, analysis, and parameter selection," IEEE Trans. Ind. Electron., vol. 48, no. 1, pp. 161-168, Feb. 2001.

[14] T. S. Kwon and S. K. Sul, "Novel antiwindup of a current regulator of a surface-mounted permanent-magnet motor for flux-weakening control," IEEE Trans. Ind. Appl., vol. 42, no. 5, pp. 1293-1300, Sep./Oct. 2006.

[15] B. J. Siebel, T. M. Rowan, and R. J. Kerkman, "Field-oriented control of an induction machine in the field-weakening region with dc-link and load disturbance rejection," IEEE Trans. Ind. Appl., vol. 33, no. 6, pp. 1578-1584, Nov./Dec. 1997.

[16] T.-S. Kwon, G.-Y. Choi, M.-S. Kwak, and S.-K. Sul, "Novel fluxweakening control of an IPMSM for quasi-six-step operation," IEEE Trans. Ind. Appl., vol. 44, no. 6, pp. 1722-1731, Nov./Dec. 2008.

[17] L. Ping-Yi and L. Yen-Shin, "Novel voltage trajectory control for fieldweakening operation of induction motor drives," IEEE Trans. Ind. Appl., vol. 47, no. 1, pp. 122-127, Jan./Feb. 2011.

[18] L. Ping-Yi and L. Yen-Shin, "Voltage control technique for the extension of DC-link voltage utilization of finite-speed SPMSM drives," IEEE Trans. Ind. Electron., vol. 59, no. 9, pp. 3392-3402, Sep. 2012.

[19] Z. Dong, Y. Yu, W. Li, B. Wang and D. Xu, "Flux-weakening control for induction motor in voltage extension region: Torque analysis and dynamic performance improvement," IEEE Trans. Ind. Electron., vol. 65, no. 5, pp. 3740-3751, May. 2018.

[20] D. Casadei, M. Mengoni, G. Serra, A. Tani, and L. Zarri, "A control scheme with energy saving and dc-link overvoltage rejection for induction motor drives of electric vehicles," IEEE Trans. Ind. Appl., vol. 46, no. 4, pp. 1436-1446, Jul./Aug. 2010.

[21] M. Mengoni, L. Zarri, A. Tani, L. Parsa, G. Serra, and D. Casadei, "High-Torque-Density Control of Multiphase Induction Motor Drives Operating Over a Wide Speed Range," IEEE Trans. Ind. Electron., vol. 62, no. 2, pp. 814-825, Feb. 2015.

[22] B. Wang, Y. Zhao, Y. Yu, G. Wang, D. Xu, and Z. Dong, "Speedsensorless induction machine control in the field-weakening region using discrete speed-adaptive full-order observer," IEEE Trans. Power Electron. , vol. 31, no. 8, pp. 5759-5773, Aug. 2016.

[23] H. Grotstollen, J. Wiesing, "Torque capability and control of a saturated induction motor over a wide range of flux weakening," IEEE Trans. on Industrial Electronics, vol. 42, no. 4, pp. 374-381, Aug, 1995.

[24] R. Sepulchre, T. Devos, F. Jadot, and F. Malrait, "Antiwindup design for induction motor control in the field weakening domain," IEEE Trans. Control Syst. Technol., vol. 21, no. 1, pp. 52-66, Jan. 2013.

[25] S. Morimoto, M. Sanada, and Y. Takeda, "Wide-speed operation of interior permanent magnet synchronous motors with high-performance current regulator," IEEE Trans. Ind. Appl., vol. 30, no. 4, pp. 920-926, Jul./Aug. 1994.

[26] S. K. Sahoo and T. Bhattacharya, "Field weakening strategy for a vector-controlled induction motor drive near the six-step mode of operation," IEEE Trans. Power Electron., vol. 31, no. 4, pp. 30433051,Apri.2016.

[27] G. Gallegos-Lopez, F. S. Gunawan, and J. E. Walters, "Current control of induction machines in the field-weakened region," IEEE Trans. Ind. Appl., vol. 43, no. 4, pp. 981-989, Jul./Aug. 2007.

[28] A. M. Khambadkone, and J. Holtz, "Compensated synchronous PI current controller in overmodulation range and six-step operation of space-vector-modulation-based vector-controlled," IEEE. Trans. Ind. Electron, vol. 49, pp. 574-580, August 2002.

[29] F. B. Del Blanco, M. W. Degner, and R. D. Lorenz, "Dynamic analysis of current regulators for ac motors using complex vectors," IEEE Trans. Ind. Appl., vol. 35, no. 6, pp. 1424-1432, Nov./Dec. 1999.

[30] F. B. Del Blanco, M. W. Degner, and R. D. Lorenz, "Current and Flux Regulation in Field-Weakening Operation," IEEE Trans. Ind. Appl., vol. 37, no. 1, pp. 42-50, Jan./Feb. 2001. 


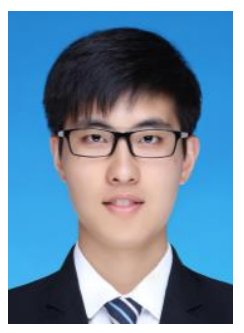

Zhen Dong (S'18) received the B.S. degree (the Hons) and M.S. degree (the Golden Thesis) in Electrical Engineering from Harbin Institute of Technology (HIT), Harbin, China, in 2016 and 2018, respectively. $\mathrm{He}$ is currently working toward the Ph.D. degree in Control Systems in the School of Electrical and Electronic Engineering, The University of Manchester, Manchester, U.K.

His research interests include high-speed ac motor drives, and nonlinear control theory and its application.

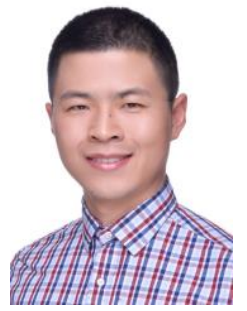

Bo Wang (S'16-M'18) was born in Shandong Province, China, in 1987. He received the B.S. degree in electrical engineering from Northwestern Polytechnical University, Xi'an, China, in 2011, and the M.S. and the $\mathrm{Ph} . \mathrm{D}$. degrees in electrical engineering from Harbin Institute of Technology, Harbin, China, in 2013 and 2017, respectively.

He joined the School of Electrical Engineering and Automation, Harbin Institute of Technology, Harbin, China, where he is currently a Lecturer of electrical engineering. He has authored more than 30 technical papers published in journals and conference proceedings. His research interests include ac motor drives, sensorless control of ac motors, and nonlinear control theories.

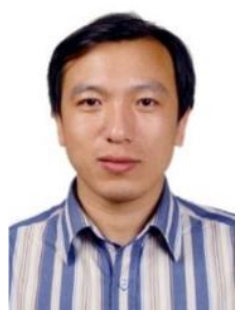

Yong Yu was born in Jilin Province, China, in 1974. He received the B.S. degree in electro- magnetic measurement and instrumentation from the Harbin Institute of Technology (HIT), where he also received the M.S. and Ph.D. degrees in electrical engineering in 1997 and 2003, respectively.maticl

From 2004 to 2014, he was an Associate Professor in the Department of Electrical Engineering, HIT, where he has been a Professor of Electrical Engineering since 2014. His current research interests include electrical motor drives, power quality mitigation, and fault diagnosis and tolerant control of inverter.

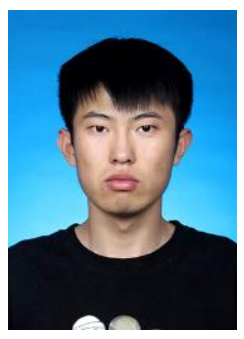

Xu Zhang (S'18) was born in Hebei Province, China, in 1994. He received the B.S. degree in electrical engineering from Harbin Engineering University, Harbin, China, in 2017. He is currently working toward the M.S. degree in electrical engineering in Harbin Institute of Technology, Harbin, China.

His research interests include high-speed induction machine drives and deadbeat direct torque control theories.

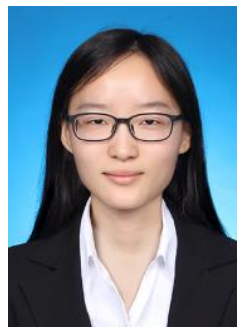

Jing Zhang was born in Henan Province, China, in 1996. She received the B.S. degree in electrical engineering from Harbin Engineering University, Harbin, China, in 2018. She is currently working toward the M.S. degree in electrical engineering in Harbin Institute of Technology, Harbin, China.

Her research interests include high-speed induction machine drives and robust control theories.

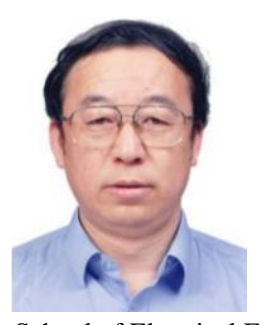

Dianguo Xu (M'97-SM'12-F'17) received the B.S. degree in Control Engineering from Harbin Engineering University, Harbin, China, in 1982, and the M.S. and the Ph.D. degrees in Electrical Engineering from Harbin Institute of Technology (HIT), Harbin, China, in 1984 and 1989 respectively.

In 1984, he joined the Department of Electrical Engineering, HIT as an Assistant Professor. Since 1994, he has been a Professor in the Department of Electrical Engineering, HIT. He was the Dean of School of Electrical Engineering and Automation, HIT from 2000 to 2010. He is now the Vice President of HIT. His research interests include renewable energy generation technology, power quality mitigation, sensorless vector controlled motor drives, high performance PMSM servo system. He published over 600 technical papers.

Dr. Xu is a fellow of IEEE, an Associate Editor of the IEEE Transactions on Industrial Electronics and IEEE Journal of Emerging and Selected Topics in Power Electronics. He serves as Chairman of IEEE Harbin Section.

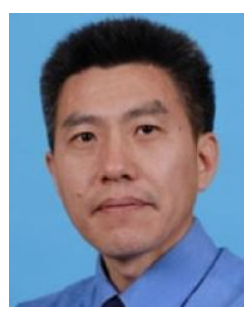

Zhengtao Ding (SM'03) received the B.Eng. degree from Tsinghua University, Beijing, China, in 1984, and the M.Sc. degree in systems and control and the Ph.D. degree in control systems from the University of Manchester Institute of Science and Technology, Manchester, U.K., in 1986 and 1989, respectively.

After working as a Lecturer with Ngee Ann Polytechnic, Singapore, for ten years, in 2003, he joined The University of Manchester, Manchester, U.K., where he is Professor of Control Systems with the School of Electrical and Electronic Engineering. He is the author of the book Nonlinear and Adaptive Control Systems (IET, 2013) and a number of journal papers. His research interests include nonlinear and adaptive control theory and their applications.

Dr. Ding serves as an Associate Editor of the IEEE Transactions on Automatic Control, Transactions of the Institute of Measurement and Control, Control Theory and Technology, Mathematical Problems in Engineering, Unmanned Systems, and the International Journal of Automation and Computing. 